\title{
FITTING OF AUDIO PROCESSORS IN PARTIAL DEAFNESS TREATMENT
}

\author{
Marek Polak ${ }^{1}$, Artur Lorens ${ }^{2,3}$ \\ ${ }^{1}$ Med-El Corporation, Innsbruck, Austria \\ ${ }^{2}$ Institute of Physiology and Pathology of Hearing, ul. Zgrupowania AK "Kampinos" 1, 01-943 Warszawa, Poland \\ ${ }^{3}$ World Hearing Center, ul. Mokra 17, Kajetany 05-830 Nadarzyn, Poland
}

Corresponding author: Marek Polak, Med-El Corporation, Innsbruck, Austria, e-mail: m.polak@ifps.org.pl

\begin{abstract}
Recently, cochlear implant (CI) eligibility criteria have broadened to include individuals with partial deafness, a condition in which, prior to implantation, a significant amount of low-frequency hearing remains. Cochlear implantation aimed for hearing preservation in partial deafness has been recognized as a new method of partial deafness treatment. However, it is not only hearing preservation that has a great influence on the performance of such users; it is also the fitting of the audio processor consisting of acoustic and electric part. In this paper the authors review results of recent studies that underline the importance of correct fitting of the audio processor in order to achieve good benefits in Electric-Acoustic Stimulation (EAS).
\end{abstract}

Key words: partial deafness treatment • electro-acoustic stimulation $\bullet$ cochlear implant $\bullet$ hearing aid

\section{AJUSTE DE PROCESADORES DE AUDIO EN EL TRATAMIENTO DE LA SORDERA PARCIAL (PDT)}

\section{Resumen}

Recientemente, los criterios de elegibilidad para implantes cocleares (IC) se han ampliado para incluir a personas con sordera parcial, una condición en la que, antes de la implantación, se mantiene una cantidad significativa de la audición a baja frecuencia. El implante coclear, cuyo objetivo es la preservación de la audición en sordera parcial, ha sido reconocido como un nuevo método de tratamiento de sordera parcial. Sin embargo, no es sólo la preservación de la audición que tiene una gran influencia en el rendimiento de dichos usuarios, sino que es también el ajuste del audio procesador que consta de una parte acústica y otra eléctrica. En este trabajo los autores hacen una revisión de los resultados de estudios recientes que ponen de manifiesto la importancia de un correcto ajuste del procesador de audio a fin de lograr buenos beneficios en la estimulación eléctrico-acústica (EAS).

Palabras clave: tratamiento de sordera parcial • estimulación electro-acústica • implante coclear • audífono

\section{AJUSTEMENT DES AUDIO PROCESSEURS DANS LE TRAITEMENT DE LA SURDITE PARTIELLE}

\section{Résumé}

Récemment, les critères d’admission aux implants cochléaires se sont élargis pour inclure les personnes atteintes de surdité partielle, un état dans lequel l'audition en basses fréquences existe dans une grande mesure avant l'implantation. L'implantation cochléaire en vue de préserver l'audition dans les cas de surdité partielle a été reconnue comme une nouvelle méthode de traitement de la surdité partielle. Toutefois, ce n’est pas seulement la préservation auditive qui a une grande influence sur la performance de ces utilisateurs, cela concerne également le montage de l'audio processeur constitué d'une partie acoustique et électrique. Dans cet article, les auteurs passent en revue les résultats d'études récentes qui soulignent l'importance du montage correct de l' audio processeur afin d'obtenir de bons effets dans la stimulation électro-acoustique (EAS).

Mots-clés: traitement de la surdité partielle $\bullet$ stimulation électro-acoustique • implant cochléaire • prothèse auditive 


\section{ПОДГОНКА ЗВУКОВЫХ ПРОЦЕССОРОВ В ЛЕЧЕНИИ ЧАСТИЧНОЙ ГЛУХОТЫ (PDT)}

\section{Краткий обзор}

В недавнее время были расширены критерии отбора в аспекте применения кохлеарного имплантата (CI) c включением пациентов с частичной глухотой, состоянием, при котором до имплантации сохраняется возможность слышать значительное количество низкочастотных звуков. Кохлеарная имплантация, целью которой является сохранение остроты слуха при частичной глухоте, была признана новым методом лечения частичной глухоты. Тем не менее, на деятельность таких пользователей влияет не только сохранение слуха, но также подгонка звукового процессора, представленного акустической и электрической частью. В настоящей работе авторы представляют обзор результатов последних исследований, делающих акцент на актуальности правильной подгонки звукового процессора с целью достижения положительных результатов электро-акустической стимуляции (ЕАS).

Ключевые слова: лечение частичной глухоты • электроакустическая стимуляция • кохлеарный имплантат • слуховое устройство

\section{Background}

Recently, cochlear implant (CI) eligibility criteria have broadened to include individuals with partial deafness, a condition in which, prior to implantation, a significant amount of low-frequency hearing remains. Cochlear implantation in partial deafness has been recognized as a new method of partial deafness treatment (PDT) [1] and can involve one of 3 approaches for 3 distinct groups of patients:

I. Electric-Acoustic Stimulation (EAS) for patients with mild to severe hearing loss at low frequencies and profound hearing loss at high frequencies. In the EAS group, low-frequency hearing is amplified and combined with electric stimulation in the same ear. This approach was first suggested and evaluated by von Ilberg and colleagues [2].

II. Electrical complement, as proposed by Skarzynski and colleagues $[1,3]$ for patients with normal or slightly elevated thresholds at low frequencies and with almost total deafness at higher frequencies. Nonamplified lowfrequency hearing is complemented by electric stimulation with a cochlear implant.

III. Electrical stimulation, used solely in the implanted ear for patients with loss of low-frequency hearing after implantation or nonfunctional preservation of hearing. Generally, non-functional hearing means that acoustic amplification does not create any additional benefit in speech discrimination. This is usually when low frequency hearing is poorer than $85 \mathrm{~dB} \mathrm{HL}$.

Several studies have shown that with appropriately designed and inserted electrodes acoustic hearing can be preserved in the majority of subjects [4-7] during cochlear implant (CI) surgery. The studies show that $20 \mathrm{~mm}$ electrode array insertion with preserved low-frequency hearing, is a highly effective method for the treatment of partial deafness [3]. However, it is not only hearing preservation that has a great influence on the performance of EAS users; it is also the fitting of the device. In this paper we will discuss some fitting aspects of the audio processors for EAS in patients with $20 \mathrm{~mm}$ electrode insertion depth.

\section{Speech processor and hearing aid in the implanted ear}

In the earliest EAS subjects, the fitting of the hearing aid (HA) component and fitting of the speech processor of the CI were done separately. Vermiere et al. [8] assessed four EAS subjects with different experience levels on eight different fitting settings. The study specifically investigated the effects of three parameters: HA amplification, frequency range of amplification (amplification range), and the lower limit of the electric frequency range (minimum electric frequency). The HA amplification was set based on the half-gain rule, or on the half-gain rule plus $6 \mathrm{~dB}$, while the amplification range was set to cover all frequencies either with a pure tone threshold better than $85 \mathrm{~dB}$ HL, or with a threshold better than $120 \mathrm{~dB}$. The minimum electric frequency was either set to 200 $\mathrm{Hz}$ (full frequency range as used for standard CI users; wide overlap), or to the falloff frequency of the audiogram (narrow overlap). The upper limit of the electric frequency range (the maximum electric frequency) was left to the default value defined in the fitting software. Results demonstrated that the narrow overlap of CI and $\mathrm{HA}$ amplification produced the best results across listening conditions. It therefore appears that a small amount of overlap between the frequency ranges used by the HA and the CI is beneficial.

The best option for the HA was considered to be the smallest possible HA, that is, an in-the-ear (ITE) HA so that the cochlear implant speech processor could be worn behind the ear. However, several problems arose from this arrangement: 1) the two devices worked independently; 2) each device was of a different size and had a different battery life; 3) the in-the-ear HAs used were working at their limits in the low frequencies; and 4) handling was complicated. Several potential EAS users refused to accept wearing two devices and many chose to use the CI only. These observations of low acceptance were confirmed in a multicentre study [9] in 18 EAS users fitted with a conventional in-the-ear HA (Oticon Adapto-P, Oticon, Denmark) and the TEMPO+ speech processor (Med-El, Innsbruck). 


\section{DUET audio processor}

With the growing number of EAS users, there was an obvious need to create a comfortable, user-friendly combined device for these subjects. In November 2005, the first hearing system to combine a speech processor and a HA, the Med-El DUET audio processor, was introduced on the market. In order to overcome the aforementioned issues, the DUET audio processor features a single microphone for the TEMPO+ speech processor (using the CIS+ strategy) and a two-channel HA (allowing $40 \mathrm{~dB}$ gain through $1800 \mathrm{~Hz}$ ) in one unit.

Helbig and her colleagues evaluated the outcomes when experienced EAS users upgraded to a DUET [10]. Nine subjects who initially used an ITE hearing aid in the implanted ear participated in this study. However, 6 subjects subsequently stopped wearing their hearing aid and were using their CI only. The reasons they gave for not wearing the ipsilateral ITE were that they considered it too cumbersome to manage 2 devices in the same ear or they found the acoustic amplification to be too soft. All subjects performed equally well in speech tests in noise and quiet, or even better, after switchover. Similar results were seen over time. Three subjects who used ipsilateral ITE before switchover performed equally afterwards, while those who used CI only did markedly better with the new device, especially in noisy conditions. Slight preference for the new system was also demonstrated with the Abbreviated Profile of Hearing Aid Benefit (APHAB) questionnaire [11].

\section{Fitting of electric and acoustic parts of the audio processor}

Polak et al. tested the effect of the lower electric frequency limit on speech test performance in 12 experienced EAS users [12]. Testing was performed under the CI (no HA; contralateral ear plugged) and DUET ( $\mathrm{HA}+\mathrm{CI}$; contralateral ear plugged) conditions. Only patients who were experienced CI and DUET users were chosen; all study participants had worn their CI for a minimum of 12 months and their DUET hearing system for at least one month. Initially, the DUET HA component was fitted based on the halfgain rule plus individual adaptations. The minimum electric frequency of the DUET CI component was either set to $200 \mathrm{~Hz}$ (full frequency range) or set as obtained from an unaided audiogram at 50, 65, and $80 \mathrm{~dB}$ HL (reduced frequency range). The maximum electric frequency was set at the default value $(8.5 \mathrm{kHz})$. For each condition, speech tests at different SNRs were obtained. For each parameter change, subjects had approximately one day to adjust. Throughout testing, the contralateral ear was plugged.

On average, in the DUET condition, best speech understanding was achieved with the minimum electric frequency set to $554 \mathrm{~Hz}$. This means that the best speech scores on average were obtained for the minimum electric frequency set to the frequency at $65 \mathrm{~dB} \mathrm{HL}$ in the audiogram. For the CI condition, best speech understanding was found with the average minimum electric frequency set to $430 \mathrm{~Hz}$. In the DUET condition, speech scores for the minimum electric frequency with the best speech scores in the DUET mode and speech scores for the minimum electric frequency with the best speech scores in the CI mode were compared. The statistical evaluation revealed a significant decrease in the speech score when testing for the minimum electric frequency, with the best speech scores in the CI mode. With the full frequency range, $78 \%$ of subjects had poorer speech test scores in the DUET condition when compared to the reduced frequency range. The difference between the minimum electric frequency for the DUET condition and the CI condition was statistically significant. This highlights the importance of fitting both the CI and HA component at initial stimulation in order to achieve the best benefit in the shortest time.

In early EAS users, the HA and speech processor were fitted separately. Patients were fitted with the electrical component only and after a certain period of time (2 to 6 months) they would be provided with the ipsilateral acoustic component as well. The above results suggest that patients should be fitted during the initial stimulation with both electric and acoustic component of the audio processor. The advantage of doing so is that subjects do not have to adjust twice for different parameter settings (i.e. minimum electric frequency) of the audio processor and thus the learning period can be decreased and patients can have the increased benefit of EAS in a shorter time. However, this is only true for patients who postoperatively benefit from ipsilateral acoustic stimulation. For subjects who have normal or near to normal hearing, or residual hearing is relatively poor at low frequencies (usually worse than $85 \mathrm{~dB}$ SPL), ipsilateral acoustic stimulation may not be beneficial at this period of time.

The above experiments showed that both electric and acoustic parameters in EAS differ from electric or acoustic stimulation only. Polak et al., as a continuation of the previous study [12], tested important acoustic and electric parameters in EAS with the goal of finding the optimized benefit for the implanted ear, and also to establish the benefits for the ipsilateral implanted ear (with hearing preservation) using the DUET audio processor [13]. The group of subjects consisted of 24 experienced adults with minimum use of CI (12 months) and minimum use of ipsilateral HA (1 month). Each subject was tested for approximately 1 week. To compare the objective speech performance under various listening conditions, clinically used monosyllable speech tests and sentence tests at various $\mathrm{S} / \mathrm{N}$ levels were tested. The minimum electric frequency of the DUET CI component was either set to 200 $\mathrm{Hz}$ (full frequency range) or it was set as obtained from an unaided audiogram at 50,65, and $80 \mathrm{~dB}$ HL (reduced frequency range), similar to the previous study by Polak et al. [12]. Firstly, subjects were tested in the E mode (no DUET acoustic component was allowed) for the following parameter change:

- Lower CI frequency: $200 \mathrm{~Hz}$, from unaided audiogram at 50,65 , and $80 \mathrm{~dB}$ HL.

Secondly, subjects were tested in the DUET mode (acoustic component of the DUET was added) for the following parameter change:

- Lower CI frequency: $200 \mathrm{~Hz}$; from unaided audiogram at 50,65 , and $80 \mathrm{~dB} \mathrm{HL}$

- Compression threshold: 40,55, $70 \mathrm{~dB}$

- LF slope: (Th500-Th250)/2, 0, $18 \mathrm{~dB} /$ octave

- Compression: 1: 1, 1: 1.33, 1: 2 
Speech Test Score $(\mathrm{N}=24 ; 18 ; 18 ; 24)$

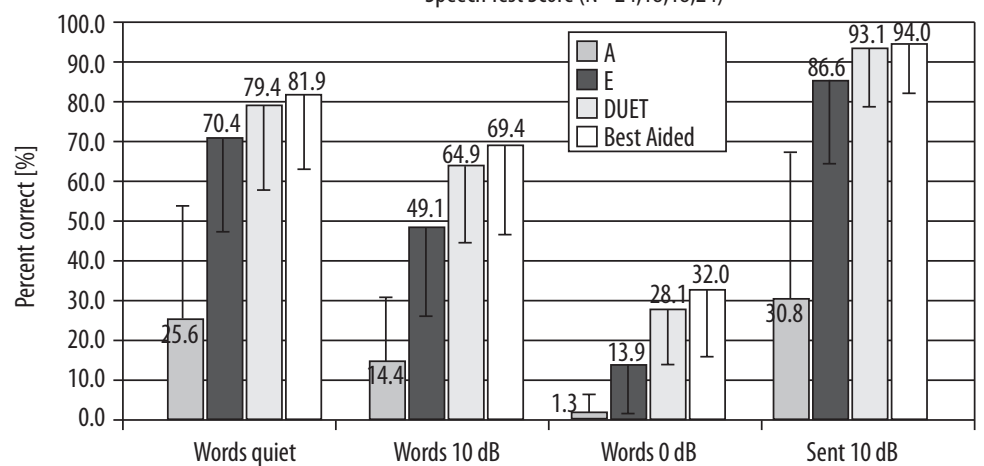

Maximum deacrease of benefit from the optimazed values

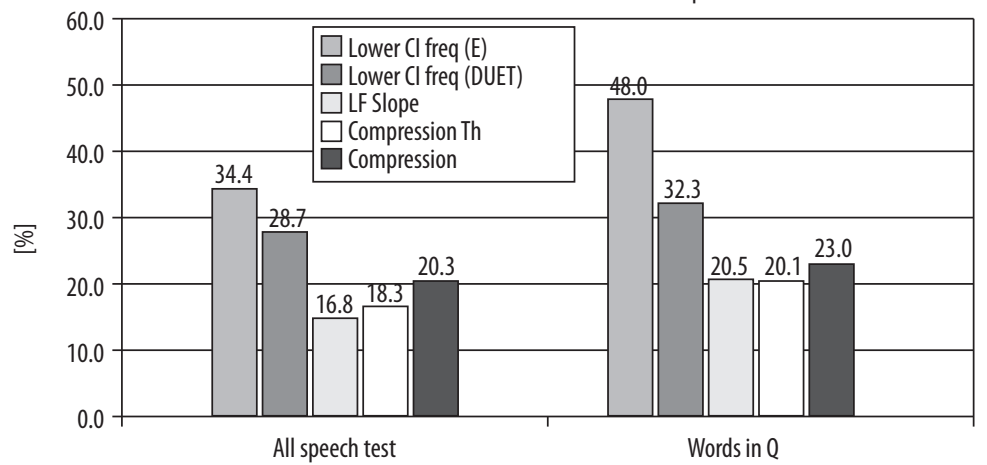

Figure 1. Speech test scores obtained at objectively best benefit.

Figure 2. The effect of a benefit decrease to a single parameter change from the optimized value.
During the whole testing week, subjects had the contralateral (unimplanted) ear plugged. Testing in the A mode (only DUET acoustic component on the implanted side was allowed) and best-aided mode (DUET acoustic and electric component on the implanted side and unplugged contralateral ear or contralateral HA was used) was performed at the end of the study. Contralateral HA was used only in the case of a subject's regular use prior to the study. Each subject tried contralateral HA; however only $25 \%$ of subjects continued to use it postoperatively. For $75 \%$ of subjects, conventional contralateral HA had either no or limited additional benefit.

Figure 1 shows the speech test results of all study subjects for four different conditions: 1) A; 2) E; 3) DUET; and 4) best-aided (contralateral ear unplugged). The scores for $\mathrm{E}$ and DUET testing were taken for the parameter settings when subjects obtained the highest speech test results.

For the optimized fitting parameters, subjects performed best in the best-aided and DUET conditions. The data confirm a large synergetic benefit for EAS subjects, as seen in previous studies. Figure 1 shows a relatively small benefit in the condition A (blue bars) similar to the preoperative speech test score data tested in quiet; a huge benefit when switching from acoustic hearing to the $\mathrm{CI}$ in quiet and in noise at $10 \mathrm{~dB}$ and $0 \mathrm{~dB} \mathrm{~S} / \mathrm{N}$ (purple bars); a huge additional benefit when adding ipsilateral (implanted ear) DUET acoustic component to the CI in quiet and in noise at $10 \mathrm{~dB}$ and $0 \mathrm{~dB} \mathrm{~S} / \mathrm{N}$ (yellow bars); and an additional small benefit when adding contralateral acoustic hearing (best-aided, contralateral ear unplugged; light blue bars). Furthermore, the results suggest that:
1. The half-gain rule seems to be a good initial fit;

2. The low-frequency slope rule ((Th500-Th250)/2) is useful for EAS subjects; however, for borderline or outsidethe-criteria subjects, the rule may not be optimal;

3. For setting the minimum CI frequency, the minimum electric frequency from the unaided audiogram $65 \mathrm{~dB}$ is recommended.

Programming parameters such as low-frequency slope, compression, compression threshold, and electric and acoustic frequency ranges play an important role in the fitting of DUET. A single parameter change in the condition E or DUET may change speech test results performed in quiet or noise by up to $35 \%$ of correct words with the mean change up to $17 \%$ of correct words. Figure 2 shows that optimized programming has a strong effect on speech test performance and quality of hearing in EAS. In the DUET only mode, a single parameter change may decrease the benefit for monosyllables in quiet up to $32 \%$. The parameters having the biggest influence on decreasing the overall benefit are lower CI frequency and compression.

\section{Benefit of speech processor and HA component incorporated in audio processor}

Lorens et al. [14] compared speech perception performance in seventeen experienced PDT adult DUET users with that of 22 experienced adult CI users. Both groups were matched for duration of hearing impairment (DUET group mean: 23.8 years; CI group mean: 19.3 years), age (DUET group mean: 43.2 years; CI group mean: 42.3 years) and gender. Subjects were programmed with the CIS+ 


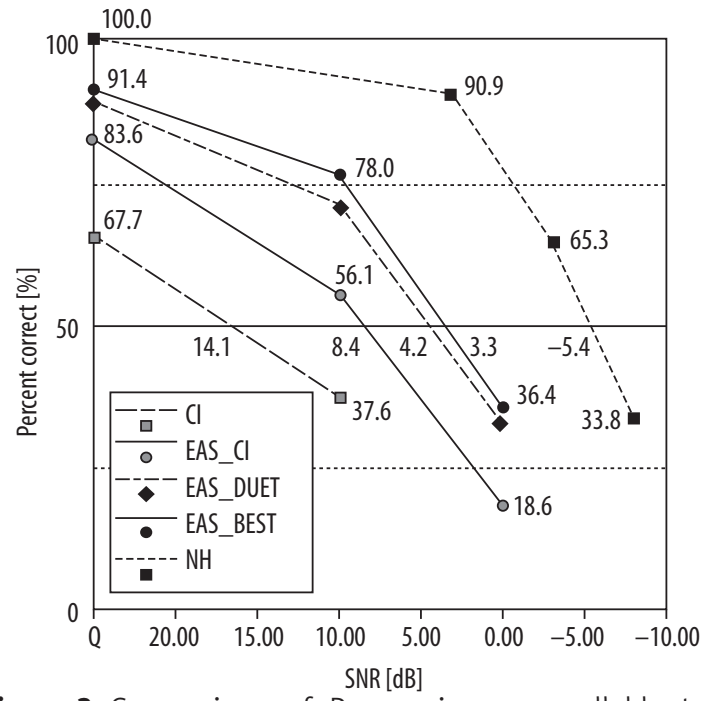

Figure 3. Comparison of Pruszewicz monosyllable test results for three groups of subjects. 1) $\mathrm{Cl}$ patients $(n=22)$ tested with their $\mathrm{Cl}$ (contralateral ear unplugged); 2) PDCI patients using the EAS concept $(n=11)$ tested in three conditions: $\mathrm{Cl}$ only (contralateral ear plugged); DUET (contralateral ear plugged) and best-aided (plus contralateral ear); and 3) normal hearing (NH) patients $(n=20)$ tested for both ears. For each condition, 50\% word-recognition performance was estimated using the linear approximation (from [14]).

speech coding strategy. The EAS subjects performed significantly better than the CI subjects. The best speech test results were those in the best-aided (DUET + contralateral ear unplugged) and DUET (contralateral ear plugged) conditions. The poorest results were obtained in the DUET HA-only condition. These data place the EAS subjects in an intermediate position between CI and normal hearing groups. The authors concluded that the combination of a HA component and a CI processor as incorporated in the
DUET audio processor is beneficial for hearing in noise and quiet (Figure 3).

\section{DUET 2 audio processor}

In February 2008 a second generation of the DUET was introduced. The Med-El DUET 2 offers new options especially aimed at increasing user comfort. These include remote control, integrated telecoil, and modular design of the audio processor. If patients use ipsilateral (implanted ear) low-frequency natural hearing without any additional amplification, by changing a battery pack and/or earhook the audio processor may be used as a regular speech processor for electrical stimulation only. Using the OPUS 2 platform, the DUET 2 allows for the new speech coding strategies.

The results of the study by Lorens et al. demonstrate that a conversion from the DUET to DUET 2 audio processor greatly improves subjective benefits and patient satisfaction [15]. Ten experienced PDT patients upgraded from the DUET to the DUET 2 were tested with the adaptive auditory speech test, monosyllabic word test, visual analogue scales, and DUET 2 user questionnaire. Tests were performed post-upgrade and compared simultaneously to the DUET in three test intervals over 3 months. Speech tests showed that there was a tendency toward better results with the DUET 2 . Subjective testing indicated that DUET 2 users preferred it for speech and musical stimuli. DUET 2 subject satisfaction was high for wearing comfort, sound quality, and in 'fine tuner' and 'private alert' features.

\section{Conclusions}

Using an audio processor in the fitting of PDT subjects showed it to be very beneficial. The data show a strong benefit for ipsilaterally (implanted side) preserved hearing. However, optimized programming has a strong effect on speech test performance and quality of hearing in the audio processor. Fitting of audio processors is an important task. In order to achieve the high benefits from the audio processors, the acoustic and electric parameters should be carefully set.

\section{References:}

1. Skarzynski H, Lorens A, Piotrowska A: A new method of partial deafness treatment. Med Sci Monit, 2003; 9(4): CS20-24

2. Von Ilberg C, Kiefer J, Tillein J et al: Electric-acoustic stimulation of the auditory system. ORL J Otorhinolaryngol Relat Spec, 1999; 61(6): 334-40

3. Skarzynski H, Lorens A: Partial deafness treatment. Cochlear Implants Int, 2010; 11(Suppl.1): 29-41

4. Skarzynski H, Lorens A, Piotrowska A, Anderson I: Preservation of low frequency hearing in partial deafness cochlear implantation (PDCI) using the round window surgical approach. Acta OtoLaryngol, 2007; 127: 41-48

5. Gantz BJ, Turner C: Combining acoustic and electrical speech processing: Iowa/Nucleus hybrid implant. Acta Otolaryngol, 2004; $124: 344-47$

6. Gstöttner W, Kiefer J, Baumgartner W et al: Hearing preservation in cochlear implantation for electric acoustic stimulation. Acta Otolaryngol, 2004; 124: 348-52
7. Skarzynski H, Lorens A, Piotrowska A, Podskarbi-Fayette R: Results of Partial Deafness Cochlear Implantation Using Various Electrode Designs Audiol Neurotol, 2009; 14(1): 39-45

8. Vermeire K, Anderson I, Flynn M, Van de Heyning P: The influence of different speech processor and hearing aid settings on speech perception outcomes in electric acoustic stimulation patients. Ear \& Hearing, 2008; 29(1): 76-86

9. Gstoettner WK, Van de Heyning P, Fitzgerlad O’Connor A et al: Electric acoustic stimulation of the auditory system: Results of a multicentre investigation. Acta Otolaryngol, 2008; 128(9): 968-75

10. Helbig S, Baumann U, Helbig M et al: A new combined speech processor for electric and acoustic stimulation - eight months experience. ORL J Otorhinolaryngol Relat Spec, 2008; 70(6): 359-65

11. Cox RM, Alexander GC: The abbreviated profile of hearing aid benefit (ABHAB). Ear Hear, 1995; 16: 176-86 
12. Polak M, Schmidt M, Lorens A et al: Fitting Paradigm in the Combined Electic-Acoustic Stimulation (EAS); 11th International Conference on Cochlear Implants, Charlotte, NC, 2007

13. Polak M, Lorens A, Helbig S et al: Fitting of the hearing system affects partial deafness cochlear implant performance. Cochlear Implants Int, 2010; 11(1): 117-21
14. Lorens A, Polak M, Piotrowska A, Skarzynski H: Outcomes of treatment of partial deafness with cochlear implantation: a DUET study. Laryngoscope, 2008; 118(2): 288-94

15. Lorens A, Zgoda M, Skarzynski H: A new audio processor for combined electric and acoustic stimulation for the treatment of partial deafness. Acta Otolaryngol, in press 